\title{
Perception of Child Abuse and Child Disciplinary Practice among Adults Abused as Children: Comparison to General Population
}

\author{
Ka Young Moon', So Young Irene Lee ${ }^{1}$, A Reum Lee, Ka Yeong An¹, Kyung Soo Jung², \\ Kyoung-II Paek ${ }^{2}$, Hyun Ah Kang ${ }^{3}$, Ji Young Kang ${ }^{3}$, and Shun Ah Chung ${ }^{3}$ \\ ${ }^{1}$ Department of Psychiatry, Soonchunhyang University Bucheon Hospital, Bucheon, Korea \\ ${ }^{2}$ Division of law, College of Law, Sookmyung Women's University, Seoul, Korea \\ ${ }^{3}$ Division of Child Welfare \& Studies, College of Human Ecology, Sookmyung Women's University, Seoul, Korea
}

\begin{abstract}
Objectives: The aim of this study was to compare differences in perception and knowledge of child abuse and child disciplinary practices according to the history of child abuse victimization.

Methods: A questionnaire survey on child abuse was conducted with 491 adults raising children. We compared the perception and knowledge of child abuse and child disciplinary practices between two groups of adults with and without a history of childhood abuse victimization.

Results: The group with a history of childhood abuse had lower levels of knowledge of child abuse $(\mathrm{F}=6.990, \mathrm{p}<0.01)$ and engaged in more negative disciplinary practices $(\mathrm{F}=5.974, \mathrm{p}<0.05)$ than those without. However, no differences in the perception of child abuse were observed between the two groups.

Conclusion: The results suggest that adults with a history of childhood abuse have lower levels of knowledge of child abuse and use more negative disciplinary practices in raising their children. This highlights the need to administer not only educational but also more direct hands-on interventions to vulnerable parents in order to foster healthy parenting and disciplinary practices.
\end{abstract}

Key Words: Child abuse; Discipline; Perception; Knowledge.

Received: October 31, 2018 / Revision: November 20, 2018 / Accepted: January 3, 2019

Address for correspondence: So Young Irene Lee, Department of Psychiatry, Soonchunhyang University Bucheon Hospital, 170 Jomaru-ro, Bucheon 14584, Korea

Tel: +82-32-621-5063, Fax: +82-32-621-6909, E-mail: irenelee@schmc.ac.kr

\section{INTRODUCTION}

The Child Welfare Act of South Korea defines the term "child abuse" as "doing harm to a child's health or welfare or committing physical, mental, or sexual violence, or cruel acts that are likely to impede normal growth of a child by adults including the child's protector, and abandoning or neglecting a child by his/her protector." According to this definition, the law categorizes child abuse into physical abuse, sexual abuse, emotional abuse, and neglect. "Physical abuse" is any act of physical violence committed by an adult against a child through which physical injury is caused or may be caused. "Sexual abuse" is any act of a sexual nature either causing a child to feel sexually ashamed, such as sexual harassment and sexual violence, or forcing or enticing a child to engage in

This is an Open Access article distributed under the terms of the Creative Commons Attribution Non-Commercial License (https://creativecommons.org/licenses/by-nc/4.0) which permits unrestricted non-commercial use, distribution, and reproduction in any medium, provided the original work is properly cited. any type of sexual activity. "Emotional abuse" is any act committed by a caregiver that may cause injury to mental health and development, including direct abuse (e.g., habitual yelling or ignoring, verbal aggression, and negative gestures or words) and indirect mental injury inflicted on a child by witnessing physical and verbal domestic violence. "Neglect" is any act of abandoning a child under one's protection without caring for basic needs including nutrition, clothing, and housing as well as appropriate rearing and healthcare. Child abuse is a serious social problem because abused children can be severely injured or even killed by the act of abuse, and are at a high risk for suicide in early adulthood [1,2]. Child abuse is known to have lingering effects, such as clinical symptoms including sleep disorder, anxiety, depressive disorder, and posttraumatic stress disorder, disruptive and aggressive behaviors [3,4], and impaired ability to form interpersonal relationships including peer and teacher attachment and later intimate relations [5-7]. 
As examined above, not only does exposure to child abuse cause short-term problems to children but can have enduring repercussions into adolescence and adulthood. These repercussions can be exacerbated when abused children become parents. The social learning theory terms this phenomenon "intergenerational transmission," suggesting that abused children observe and learn their parents' behavior and have a greater tendency to maltreat their own children [8]. This also reflects the phenomenon that the characteristics of interactions between children and their caregivers are internalized by children and carried on into adulthood, eventually influencing their relationships with their own children [9]. Given these theories and research results, parents whose caregivers exposed them to aggressive, violent discipline and rejection in their childhood are more likely to discipline their own children in the same negative way [10]. In this regard, a previous study demonstrated that parents with abusive childhood experiences are more likely to use harsh discipline toward their own children [11]. However, except for this paper, research on the association between childhood exposure to abuse and parental child disciplinary practices has hardly been undertaken in South Korea. Therefore, the present study aims to identify the relationship between childhood exposure to abuse and parental child disciplinary practices.

Most South Korean studies related to child abuse have revolved around determining the levels of knowledge and perception of child abuse and child abuse report intention among those legally obligated to report child abuse, such as kindergarten and primary school teachers $[12,13]$ and child welfare service and healthcare workers [14]. However, research on the awareness of child abuse among the general population or parents has been limited to investigating the level of parents' knowledge and perception of child abuse [15]. According to "Child Abuse \& Neglect," the 2016 report by the National Child Protection Agency, parents accounted for the largest proportion of child abuse offenders with $80.5 \%$ [16]. This highlights the importance of research on parental perceptions of child abuse, especially the difference in the level of perception between parents with a history of childhood abuse and those without, given the possibility of intergenerational transmission of experience of parenting practices. According to a study on the levels of perception of child abuse among kindergarten teachers, the higher the perception, the less likely they were to commit an act of child abuse [17]. From this, it follows that the level of perception of child abuse may be considered a potential protective factor against child-abusive behavior. Drawing on this assumption, this study aims to determine whether there are differences in the levels of knowledge and perception of child abuse between parents with a history of childhood abuse and those without.

To sum up, not only can parents who were victims of childhood abuse suffer from the lingering effects of victimization but their abusive childhood experiences can also adversely affect their relationships with their own children. However, there is a lack of research on such relationships in South Korea. The aim of this study is, therefore, twofold: first, investigating the possibility of the intergenerational transmission of child abuse by comparing the child disciplinary practices of parents with and without a history of childhood abuse; second, comparing the levels of knowledge and perception of child abuse between these two groups.

\section{METHODS}

\section{Participants}

For the recruitment of survey participants, we used the data collected in the "Survey of Bucheon Citizens' Perception of Child Abuse" conducted with 1000 adults aged 20 to 65 who visited a public institution within Bucheon City in October and November 2015. For analysis purposes, we used the data of 491 visitors who had children (125 men, 366 women). The survey data were collected by face-to-face interviews using a questionnaire. Prior to conducting the survey, surveyors explained the purpose of the study, survey content and method, and the process of personal information collection and handling to the potential participants and received written informed consent. Surveyors were selected from among undergraduate students from mental health-related programs with mental health-related survey experience, and standardization training was provided to ensure interrater reliability.

The survey interviews were conducted at Bucheon City Mental Health Center in 2015 after approval by the Institutional Review Board of Soonchunhyang University Hospital Bucheon (IRB Number: 201510011).

\section{Assessment scales}

\section{Demographic and clinical characteristics}

Demographic variables were age, sex, marital status, educational level, economic status, religious affiliation, and presence/absence of school-aged children. Variables related to clinical characteristics were alcohol use, psychiatric illness, history of psychiatric treatment, and history of hospitalization. As for psychiatric illness, the participants were asked whether they had suffered or were suffering from any of the following conditions: depressive disorder, anxiety disorder, bipolar disorder, schizophrenia, adjustment disorder, somatoform disorder, sleep disorder, personality disorder, dementia, organic mental disorders, mental retardation, and 
developmental disabilities. It was also checked whether they had undergone psychiatric treatment and hospitalization.

\section{History of childhood abuse}

The participants were asked if they had experienced physical, sexual, or emotional abuse or neglect from their caregivers or significant adults. To assess the history of childhood abuse, we used a four-item subscale, one for each type of abuse, to be answered with either "yes" (1) or "no" (2).

\section{Knowledge of child abuse}

For measurement of the level of knowledge of child abuse, we prepared a 12 -item assessment scale by partially modifying the items related to the perception of child abuse used in Hong and Lee [15] and those related to the knowledge of child abuse used in Kim [12]. The items covered contents related to the names and phone numbers of the institutions providing help to abused children, legal protection provided for informants, and characteristics of child abuse. The participants were supposed to answer each item with either "yes" (1) or "no" (2). To calculate the score of knowledge of child abuse, each correct answer received 1 point and each incorrect answer 0 points. The sum of 12 points was divided by 12 ; that is, the closer the mean score to 1 , the higher the level of knowledge of child abuse.

\section{Perception of child abuse}

For measurement of the level of perception of child abuse, we used the 29-item assessment scale developed by Hong and Lee [15]. The 29 items are grouped into four subscales: physical abuse, emotional abuse, sexual abuse, and neglect, with each item rated on a five-point Likert scale (1=definitely no, $5=$ definitely yes). For analysis, the mean scores of all items were calculated, and the closer the means to 5 , the higher the level of perception of child abuse.

\section{Child disciplinary practices}

For a quantitative analysis of participants' child disciplinary practices, we derived the relevant items from the questionnaire used in the original Ontario Child Health Study (OCHS) [18]. The first OCHS was conducted in 1983 to prospectively follow a large cohort of children and adolescents, assessing their physical health, psychiatric conditions, and developmental course. We translated and used questions from the seven-item parental disciplinary style subscale for when a child misbehaves: 1) explaining to the child, 2) sending the child to his/her room, 3) beating the child by hand, 4) beating the child with a rod or other objects, 5) banning the child from doing something that he/she likes, 6) grabbing and shaking the child, and 7) punishing the child. Each item was rat- ed on a four-point Likert scale ranging from 1 (never) to 4 (always). The closer the score is to 4 , the higher the frequency of the method used for child discipline. Item 1 , which is a positive disciplinary method, was reverse scored, and the closer the mean score to 4 , the higher the frequency of resorting to negative parental disciplinary practices.

\section{Statistical analysis}

Descriptive statistics were used to present the basic demographic characteristics of the participants. Data were analyzed using the t-test and chi-square test to compare the demographic and clinical characteristics between the two groups. In order to investigate the association between the levels of knowledge and perception of child abuse and the negative parental discipline of childhood in both groups, we conducted a correlation analysis for each group. Furthermore, an analysis of covariance was performed to determine the intergroup differences in the level of perception and knowledge of child abuse and child discipline, using the demographic and clinical characteristics that showed significant intergroup differences as control variables. Statistical analysis was performed using SPSS 18.0 for Windows (SPSS Inc., Chicago, IL, USA).

\section{RESULTS}

\section{Demographic characteristics (Table 1)}

Sixty-eight out of 491 participants (13.8\%) answered affirmatively to the question on whether they had been victims of one or more types of childhood abuse, and the rest $(n=423$, 86.2\%) answered negatively. Among the demographic characteristics, marital status demonstrated a significant intergroup difference $\left(\chi^{2}=10.78, \mathrm{p}<0.05\right)$ : the group with a history of childhood abuse had a higher percentage of separation or divorce. No statistically significant intergroup differences were observed in other demographic variables.

\section{Clinical characteristics (Table 2)}

There were significant intergroup differences with regard to psychiatric illness $\left(\chi^{2}=58.8, p<0.001\right)$, with a significantly higher proportion of the group with than without a history of childhood abuse reporting the presence of psychiatric disorders (29.4\% vs. $4.9 \%)$. This was most evident in the case of depressive disorder $\left(\chi^{2}=38.55, \mathrm{p}<0.001\right)$, sleep disorder $\left(\chi^{2}=\right.$ $12.39, \mathrm{p}<0.001)$, and undiagnosed mental problems $\left(\chi^{2}=9.02\right.$, $\mathrm{p}<0.01)$. Accordingly, higher proportions of the group with than without a history of childhood abuse reported current and past history of mental illness-related treatment $(10.3 \%$ vs. $0.9 \%$, and $2.9 \%$ vs. $0.7 \%$, respectively) and psychiatric hospitalization ( $16.2 \%$ vs. $3.1 \%)$, with statistical significance 
Table 1. Demographic characteristics of subjects

\begin{tabular}{|c|c|c|c|c|}
\hline & $\begin{array}{l}\text { With history of childhood } \\
\text { abuse }(n=68)\end{array}$ & $\begin{array}{c}\text { Without history of } \\
\text { childhood abuse }(n=423)\end{array}$ & Total $(n=491)$ & $\operatorname{tor} \chi^{2}$ \\
\hline & Mean (SD or \%) & Mean (SD or \%) & Mean (SD or \%) & \\
\hline Age (years) & $48.69(8.67)$ & $48.42(8.55)$ & $48.46(8.55)$ & 0.242 \\
\hline Sex & & & & 0.256 \\
\hline Male & $19(27.9)$ & $106(25.1)$ & $125(25.5)$ & \\
\hline Female & $49(72.1)$ & $317(74.9)$ & $366(74.5)$ & \\
\hline Marriage & & & & $10.78^{*}$ \\
\hline Married, cohabitation & $59(86.8)$ & $388(91.7)$ & $447(91.0)$ & \\
\hline Separation, divorce & $8(11.8)$ & $16(3.8)$ & $24(4.9)$ & \\
\hline Bereavement & $0(0)$ & $11(2.6)$ & $11(2.2)$ & \\
\hline Education & & & & 4.95 \\
\hline$<6$ years & $3(4.4)$ & $5(1.2)$ & $8(1.6)$ & \\
\hline$<9$ years & $4(5.9)$ & $19(4.5)$ & $23(4.7)$ & \\
\hline$<12$ years & $29(42.6)$ & $216(51.1)$ & $245(49.9)$ & \\
\hline Over 12 years & $31(45.6)$ & $182(43.0)$ & $213(43.4)$ & \\
\hline Economic status & & & & 4.36 \\
\hline Low & $5(7.4)$ & $24(5.7)$ & $29(5.9)$ & \\
\hline Medium low & $17(25.0)$ & $76(18.0)$ & $93(18.9)$ & \\
\hline Medium & $35(51.5)$ & $257(60.8)$ & $292(59.5)$ & \\
\hline Medium high & $11(16.2)$ & $55(13.0)$ & $66(13.4)$ & \\
\hline High & $0(0)$ & $8(1.9)$ & $8(1.6)$ & \\
\hline Religions & & & & 9.17 \\
\hline No religions & $14(20.6)$ & $161(38.1)$ & $175(35.6)$ & \\
\hline Christianity & $28(41.2)$ & $123(29.1)$ & $151(30.8)$ & \\
\hline Buddhism & $9(13.2)$ & $60(14.2)$ & $69(14.1)$ & \\
\hline Catholic & $15(22.1)$ & $70(16.5)$ & $85(17.3)$ & \\
\hline Others & $2(2.9)$ & $8(1.9)$ & $10(2.0)$ & \\
\hline \multicolumn{5}{|l|}{ School-aged children } \\
\hline Yes & $34(50.0)$ & $188(44.4)$ & $222(45.2)$ & 0.745 \\
\hline No & $33(48.5)$ & $229(54.1)$ & $262(53.4)$ & \\
\hline
\end{tabular}

Independent t-test for comparison of mean age and chi-square test for sex, marriage, education, economic status, religions, school-aged children. ${ }^{*} p<0.05$. SD: standard deviation

Table 2. Comparison of clinical characteristics between groups

\begin{tabular}{|c|c|c|c|c|}
\hline & $\begin{array}{l}\text { With history of childhood } \\
\text { abuse }(n=68)\end{array}$ & $\begin{array}{c}\text { Without history of } \\
\text { childhood abuse }(n=423)\end{array}$ & Total $(n=491)$ & $\operatorname{tor} \chi^{2}$ \\
\hline & Mean (SD or \%) & Mean (SD or \%) & Mean (SD or \%) & \\
\hline Alcohol history & $2.20(1.14)$ & $2.13(1.18)$ & $2.14(1.09)$ & 0.456 \\
\hline Psychiatric illness & & & & $58.8^{*}$ \\
\hline No & $48(70.6)$ & $402(95.0)$ & $450(91.6)$ & \\
\hline Yes & $20(29.4)$ & $21(4.9)$ & $41(8.3)$ & \\
\hline History of treatment & & & & $23.89 *$ \\
\hline Never & $48(70.6)$ & $317(74.9)$ & $365(74.3)$ & \\
\hline Current & $7(10.3)$ & $4(0.9)$ & $11(2.2)$ & \\
\hline Prior & $2(2.9)$ & $3(0.7)$ & $5(1.0)$ & \\
\hline History of hospitalization & & & & $23.07^{*}$ \\
\hline No & $52(76.5)$ & $396(93.6)$ & $448(91.2)$ & \\
\hline Yes & $11(16.2)$ & $13(3.1)$ & $24(4.9)$ & \\
\hline
\end{tabular}

Independent t-test for comparison of alcohol history and chi-square test for psychiatric illness, history of treatment, history of hospitalization. ${ }^{*} p<0.001$. SD: standard deviation 
$\left(\chi^{2}=23.89, \mathrm{p}<0.001\right.$ and $\chi^{2}=23.07, \mathrm{p}<0.001$, respectively $)$.

\section{Correlations between Levels of Knowledge and Perception of Child Abuse and Negative Child Disciplinary Practices (Table 3)}

We computed a correlation matrix by calculating the correlation coefficients between all possible pairs of the variables used for analysis (level of knowledge, level of perception, child discipline, and seven items of child disciplinary practices) for both groups. The results demonstrated a positive correlation between knowledge and perception in the group without a history of childhood abuse $(r=0.270, p<0.01)$, but no significant correlation in the group with a history of childhood abuse. The correlation coefficients of the knowledge/perception and discipline variable pairs were not statistically significant in both groups. In other words, no significant correlations were observed between the levels of perception and knowledge of child abuse and negative child disciplinary practices.

\section{Differences in Levels of Knowledge and Perception of Child Abuse Depending on the Experience of Childhood Abuse (Table 4)}

Intergroup differences in the levels of knowledge and per-

Table 3. Correlation of perception level, knowledge level and discipline

\begin{tabular}{|c|c|c|c|c|c|c|c|c|c|c|}
\hline & Knowledge & Perception & Discipline & Iteml & Item2 & Item3 & Item4 & Item5 & Item6 & Item7 \\
\hline \multicolumn{11}{|l|}{ Knowledge } \\
\hline \multirow[t]{2}{*}{ Perception } & $0.23^{*}$ & & & & & & & & & \\
\hline & $\left(0.28^{\dagger}\right)$ & & & & & & & & & \\
\hline \multirow[t]{2}{*}{ Discipline } & -0.02 & $-0.21^{*}$ & & & & & & & & \\
\hline & $(-0.03)$ & $(-0.07)$ & & & & & & & & \\
\hline \multirow[t]{2}{*}{ Iteml } & -0.17 & 0.16 & $-0.27^{*}$ & & & & & & & \\
\hline & $\left(0.13^{\dagger}\right)$ & $\left(0.11^{*}\right)$ & $\left(-0.31^{\dagger}\right)$ & & & & & & & \\
\hline \multirow[t]{2}{*}{ Item2 } & 0.07 & 0.00 & $0.61^{\dagger}$ & 0.00 & & & & & & \\
\hline & $(0.05)$ & $(-0.02)$ & $\left(0.61^{\dagger}\right)$ & $(0.05)$ & & & & & & \\
\hline \multirow[t]{2}{*}{ Item3 } & -0.13 & -0.17 & $0.76^{\dagger}$ & 0.011 & $0.35^{\dagger}$ & & & & & \\
\hline & $(-0.06)$ & $(-0.07)$ & $\left(0.71^{\dagger}\right)$ & $(-0.07)$ & $\left(0.31^{\dagger}\right)$ & & & & & \\
\hline \multirow[t]{2}{*}{ Item4 } & -0.06 & -0.11 & $0.82^{\dagger}$ & -0.01 & $0.40^{\dagger}$ & $0.72^{\dagger}$ & & & & \\
\hline & $(-0.05)$ & $(-0.03)$ & $\left(0.72^{\dagger}\right)$ & $(0.03)$ & $\left(0.33^{\dagger}\right)$ & $\left(0.55^{\dagger}\right)$ & & & & \\
\hline \multirow[t]{2}{*}{ Item5 } & -0.04 & -0.10 & $0.54^{\dagger}$ & 0.12 & $0.27^{\dagger}$ & $0.35^{\dagger}$ & $0.39^{\dagger}$ & & & \\
\hline & $(0.06)$ & $(0.01)$ & $\left(0.60^{\dagger}\right)$ & $(0.08)$ & $\left(0.27^{\dagger}\right)$ & $\left(0.39^{\dagger}\right)$ & $\left(0.39^{\dagger}\right)$ & & & \\
\hline \multirow[t]{2}{*}{ Item6 } & -0.12 & -0.17 & $0.70^{\dagger}$ & 0.02 & $0.42^{\dagger}$ & $0.54^{\dagger}$ & $0.55^{\dagger}$ & $0.24^{*}$ & & \\
\hline & $(-0.03)$ & $(-0.01)$ & $\left(0.58^{\dagger}\right)$ & $(-0.60)$ & $\left(0.29^{\dagger}\right)$ & $\left(0.46^{\dagger}\right)$ & $\left(0.38^{\dagger}\right)$ & $\left(0.27^{\dagger}\right)$ & & \\
\hline \multirow[t]{2}{*}{ Item7 } & -0.05 & -0.16 & $0.71^{\dagger}$ & -0.01 & $0.32^{\dagger}$ & $0.44^{\dagger}$ & $0.63^{\dagger}$ & $0.36^{\dagger}$ & $0.38^{\dagger}$ & \\
\hline & $(0.03)$ & $(0.01)$ & $\left(0.68^{\dagger}\right)$ & $(0.04)$ & $\left(0.35^{\dagger}\right)$ & $\left(0.40^{\dagger}\right)$ & $\left(0.53^{\dagger}\right)$ & $\left(0.36^{\dagger}\right)$ & $\left(0.34^{\dagger}\right)$ & \\
\hline \multirow[t]{2}{*}{ Mean } & 0.59 & 4.39 & 1.72 & 2.77 & 1.68 & 1.59 & 1.63 & 1.94 & 1.27 & 1.75 \\
\hline & $(0.62)$ & $(4.44)$ & (1.59) & $(2.93)$ & $(1.64)$ & $(1.41)$ & $(1.52)$ & $(1.72)$ & $(1.11)$ & $(1.66)$ \\
\hline \multirow[t]{2}{*}{ SD } & 0.17 & 0.50 & 0.43 & 0.88 & 0.70 & 0.69 & 0.62 & 0.67 & 0.64 & 0.67 \\
\hline & $(0.16)$ & $(0.46)$ & $(0.37)$ & $(0.86)$ & $(0.76)$ & $(0.55)$ & $(0.58)$ & $(0.61)$ & $(0.35)$ & $(0.63)$ \\
\hline
\end{tabular}

Item 1: positive discipline, Item2-7: negative discipline. Parenthesis: the group without history of childhood abuse. ${ }^{*} p<0.05,{ }^{\dagger} p<$ 0.01. SD: standard deviation

Table 4. ANCOVA for comparison of perception and knowledge level about child abuse between groups

\begin{tabular}{|c|c|c|c|c|}
\hline & With history of childhood abuse $(n=68)$ & Without history of childhood abuse $(n=423)$ & 5 & \\
\hline & Mean (SE) & Mean (SE) & 1 & $\beta$ \\
\hline Knowledge level & $0.57(0.20)$ & $0.62(0.08)$ & $6.990^{*}$ & 0.009 \\
\hline Perception of abuse & $4.41(0.06)$ & $4.46(0.23)$ & 0.873 & 0.351 \\
\hline Physical abuse & $4.51(0.55)$ & $4.53(0.22)$ & 0.060 & 0.806 \\
\hline Emotional abuse & $4.29(0.70)$ & $4.43(0.28)$ & 3.331 & 0.069 \\
\hline Sexual abuse & $4.69(0.48)$ & $4.73(0.19)$ & 0.024 & 0.877 \\
\hline Neglect & $4.20(0.81)$ & $4.21(0.32)$ & 0.646 & 0.422 \\
\hline
\end{tabular}

ANCOVA, adjusted by marriage, psychiatric illness, history of treatment, history of hospitalization. *p<0.01. ANCOVA: analysis of covariance, SE: standard error 
Table 5. ANCOVA for comparison of discipline between groups

\begin{tabular}{|c|c|c|c|c|}
\hline & With history of childhood abuse $(n=68)$ & Without history of childhood abuse $(n=423)$ & \multirow{2}{*}{$\mathrm{F}$} & \multirow{2}{*}{$\mathrm{p}$} \\
\hline & Mean (SE) & Mean (SE) & & \\
\hline \multicolumn{5}{|c|}{ Negative discipline } \\
\hline Total score & $1.70(0.16)$ & $1.55(0.15)$ & $5.974^{*}$ & 0.015 \\
\hline Item 1 & $2.61(0.34)$ & $2.60(0.34)$ & 0.001 & 0.976 \\
\hline Item 2 & $2.32(0.29)$ & $2.23(0.29)$ & 0.499 & 0.481 \\
\hline Item 3 & $1.45(0.23)$ & $1.17(0.23)$ & $8.529^{\dagger}$ & 0.004 \\
\hline Item 4 & $1.39(0.25)$ & $1.24(0.25)$ & 2.219 & 0.137 \\
\hline Item 5 & $1.90(0.25)$ & $1.61(0.25)$ & $7.795^{\dagger}$ & 0.006 \\
\hline Item 6 & $1.37(0.16)$ & $1.21(0.16)$ & $5.427^{*}$ & 0.020 \\
\hline Item 7 & $1.38(0.24)$ & $1.27(0.24)$ & 1.192 & 0.276 \\
\hline
\end{tabular}

ANCOVA, adjusted by marriage, psychiatric illness, history of treatment, history of hospitalization, knowledge level. ${ }^{*} p<0.05$, ${ }^{t} p<0.01$. ANCOVA: analysis of covariance, SE: standard error

ception of child abuse were analyzed, with the variables that had shown significant intergroup difference (marital status, psychiatric illness, and history of treatment and hospitalization) controlled for. As a result, a significant intergroup difference was found in the level of knowledge $(F=6.990, p<0.01)$, but not in the level of perception of child abuse.

\section{Differences in Child Disciplinary Practices Depending on the Experience of Childhood Abuse (Table 5)}

Intergroup differences in child disciplinary practices were analyzed, with the variables that had shown significant intergroup difference (marital status, psychiatric illness, history of treatment and hospitalization, and level of knowledge) controlled for. As a result, a significant intergroup difference was found in the total score of negative discipline $(\mathrm{F}=5.974$, $\mathrm{p}<0.05)$. Broken down to individual items of child disciplinary practices, significant intergroup differences were found in three items: beating the child by hand, banning the child from doing something that he/she likes, and grabbing and shaking the child $(\mathrm{F}=8.529, \mathrm{p}<0.01, \mathrm{~F}=7.795, \mathrm{p}<0.01$, and $\mathrm{F}=$ $5.427, \mathrm{p}<0.05$, respectively). No significant intergroup differences were found in the remaining four items: explaining to the child, sending the child to his/her room, beating the child with a rod or other objects, and punishing the child.

\section{DISCUSSION}

This study investigated differences in the levels of knowledge and perception of child abuse and child disciplinary practices between parents with a history of childhood abuse and those without. Given that the greatest proportion of child abuse is inflicted by parents and in light of the well-known phenomenon of intergenerational transmission [8], there is a need to examine the related aspects in parents with a history of childhood abuse and to adopt preventive approaches. This study focused on understanding the differences in dis- ciplinary practices and knowledge and perception of child abuse between parents with a history of childhood abuse and those without in order to present a theoretical basis and rationale for such preventive approaches. In this section, important results are summarized and their impacts are discussed.

First, comparisons of demographic and clinical characteristics between parents with a history of childhood abuse and those without revealed that the former had a higher prevalence of psychiatric illness, and a significantly higher proportion had undergone treatment and hospitalization for psychiatric conditions. Specifically, significant intergroup differences were observed in sleep disorder and depressive disorder, which is consistent with previous research suggesting that adults exposed to childhood abuse are more likely to exhibit long-term emotional instability [19]. In marital status, parents with a history of childhood abuse showed significantly higher percentages of separation and divorce, which can be interpreted in the same vein as the results of previous studies that childhood exposure to abuse works as a factor hampering the formation and maintenance of stable and intimate relationships in adulthood [20,21].

Second, whereas the level of knowledge of child abuse was positively correlated with the level of perception of child abuse in the group without a history of childhood abuse, no significant correlation was observed between these variables in the group with a history of childhood abuse. In this study, the level of perception of child abuse was measured as a variable for simply ascertaining whether a given situation is a case of child abuse or not, whereas the focus of the measurement of the level of knowledge was on determining whether the participants had practical knowledge of how to respond to child abuse, such as reporting a case and relevant legal aspects. These results suggest the presence of a potential factor hampering the effort to acquire the knowledge necessary for responding to a perceived case of child abuse in the case of the group with a history of childhood abuse, unlike 
the group without. In both groups, no direct correlations were observed between the levels of knowledge and perception of child abuse and child disciplinary practices. With regard to the knowledge variable, considering the finding of previous research that knowledge about negative activities such as smoking has no direct association with a positive health attitude [22], it can be assumed that there is no direct association between accumulating knowledge in a specific area and changing the related behavior. Therefore, elevating the level of knowledge of child abuse alone is not a sufficient condition for parents to change their attitudes toward their child disciplinary practices. With regard to the perception variable, the result of this study is not in agreement with that of a previous study according to which the higher the level of perception of a kindergarten teacher, the lower the possibility of committing child abuse [17]. This may be ascribable to the characteristics specific to the respective survey participants or the differences in the relational characteristics between parent-child and teacher-student pairs. This aspect needs to be investigated in detail in a future study.

Third, no significant intergroup difference was observed in the level of perception when measured with marital status, psychiatric illness, and history of treatment and hospitalization controlled for, unlike the level of knowledge, which showed a significant intergroup difference, whereby the parents with a history of childhood abuse had a lower average level of knowledge than those without a history of childhood abuse. In this regard, previous studies reported that people with interpersonal traumatic experience including child abuse strongly tend to show experiential avoidance, that is, avoiding negatively perceived personal experience and trying to inhibit or transform such experience [23,24]. This suggests the possibility that experiential avoidance may act as a negative factor hampering access to information about trauma or acquiring the related knowledge in participants exposed to childhood abuse. In other words, whereas there is little intergroup difference in the level of perception of child abuse itself, the participants exposed to childhood abuse are reluctant in making efforts to acquire concrete information about child abuse and accumulate related knowledge.

Fourth, the participants exposed to childhood abuse were found to resort to negative child discipline more frequently than those not exposed to childhood abuse, even when the variables that had shown significant intergroup difference, namely marital status, psychiatric illness, history of treatment and hospitalization, and level of knowledge, were controlled for. This finding supports previous research that parents exposed to childhood abuse are more likely to resort to harsh child disciplinary measures [11]. Among the items of child disciplinary practices, beating the child by hand, banning the child from doing something that he/she likes, and grabbing and shaking the child were disciplinary measures frequently used by the parents with a history of childhood abuse, with a significant intergroup difference. No significant intergroup differences were found in the other disciplinary measure, namely explaining to the child, sending the child to his/her room, beating the child with a rod or other objects, and punishing the child. This may be attributable to the fact that the survey participants belong to a generation, considering their mean age of 48.46 years, for which disciplinary actions involving the use of a rod or punishment were common disciplinary measures used for educational purposes, although the general perception of such actions is changing. This may explain the use of these disciplinary measures by the parents without a history of childhood abuse as well. In a future study, child disciplinary styles in different age groups need to be examined in order to trace the changing perception of child discipline in South Korea. Unlike these deliberately administered disciplinary measures, disciplinary actions of beating by hand or grabbing and shaking are punishments intended to cause physical pain in a state of uncontrolled emotion. Considering the fact that previous research has demonstrated that adults exposed to childhood abuse have difficulties controlling their emotions [25], parents with a history of childhood abuse are more likely to use disciplinary measures that spontaneously express their emotion, especially anger, in comparison with parents without a history of childhood abuse [26]. This may be interpreted as the effect of intergenerational transmission of the negative discipline they themselves received.

As revealed by the results, parents with a history of childhood abuse had higher percentages of problems in psychiatric health and intimate interpersonal relationships in comparison with parents without a history of childhood abuse. Furthermore, the former had a lower average level of knowledge of child abuse and used negative discipline more frequently than the latter, although there were no direct associations between the levels of knowledge and perception of child abuse and negative child disciplinary practices. These results suggest that individuals repeatedly exposed to parental violence and negative discipline are not only reluctant to acquire knowledge of child abuse but also strongly tend to apply similar disciplinary measures to their own children by directly modeling on the negative discipline they received from their parents. This highlights the necessity of providing interventions that go beyond simple knowledge-centered education in order to prevent the intergenerational transmission of child abuse. In some countries, in an effort to prevent the vicious cycle of abuse, proactive interventions are ad- 
ministered to mothers or pregnant women classified as child abuse high-risk groups by visiting their homes and educating them on how to use healthy disciplinary measures. Some studies reported positive effects of such interventions, such as reduced use of violence or harsh discipline and increased potential for providing positive discipline [27-29]. In South Korea as well, various parenting interventions have been provided to parents in the general population with statistically significant positive outcomes in parenting attitudes and practices in the intervention groups compared with the controls [30]. Judging from these research outcomes, it is considered crucial to develop and administer parenting interventions specialized for vulnerable parents with a history of child abuse.

Three aspects may be pointed out as the limitations of this study. First, among the participants, there are parents with adult children $(n=318)$ besides parents with children under 18 years of age $(n=258)$. This means more than half of the participants responded from their memory of past child disciplinary practices, and the related recall bias may have influenced the results. This needs to be corrected by a future study with participants with preschoolers and school-age children.

Second, the subscale regarding the history of child abuse contained four items, that is, one item for each type of child abuse. This relies on the participants' subjective memory and does not reflect the severity of abuse. These drawbacks need to be addressed in a future study with more detailed items asking about concrete experience, instead of items with binary answers (yes/no) to the experience of abuse, and quantitative assessment of its severity.

Third, the subscale regarding child disciplinary practices separately analyzed seven measures, with only one positive disciplinary practice among them. In a future study, it is necessary to use a multilayered scale with more detailed items regarding disciplinary style or parenting attitude in order to systematically explore the association between different categories of disciplinary style and experience of childhood abuse.

Despite these limitations, this study is significant in that it investigated whether parents with a history of childhood abuse are likely to use harsh disciplinary measures more frequently than parents without a history of childhood abuse, given the fact that parental child abuse accounts for the greatest proportion of child abuse. In order to effectively prevent child abuse in light of the likelihood of intergenerational transmission, it is essential to consider the parents' childhood experience. The major implication of the findings of this study is that in addition to appropriate education programs to foster healthy parenting and disciplinary behaviors in vulnerable parents, it is necessary to administer more direct hands-on interventions that go beyond conventional educa- tion so that high-risk parents can practice and experience positive disciplinary practices.

\section{CONCLUSION}

The results of this study indicated no significant difference in the average level of perception of child abuse between parents with a history of child abuse and those without; however, the former had a lower average level of knowledge of child abuse and a higher propensity to use negative disciplinary measures than the latter. This highlights the need to administer not only educational interventions but also more direct and concrete hands-on interventions to vulnerable parents in order to foster healthy parenting and disciplinary attitudes and practices.

\section{Acknowledgments}

This study was supported by the research fund of Soonchunhyang University.

\section{Conflicts of Interest}

The authors have no potential conflicts of interest to disclose.

\section{REFERENCES}

1) Young JC, Widom CS. Long-term effects of child abuse and neglect on emotion processing in adulthood. Child Abuse Negl 2014; 38:1369-1381.

2) Kim JY, Jang YE, Lee SJ. A study on the effect of negligence, emotional abuse and physical abuse experience from parents on adolescents' suicidal behavior: mediating effect of committing school violence. Sch Soc Work J 2013;25:157-183.

3) Shin EY, Cheon KA, Jhung K, Song DH, Kim SH. The effect of sexual abuse on posttraumatic psychiatric symptoms in children and adolescents with sexual abuse. J Korean Acad Child Adolesc Psychiatry 2015;26:38-44.

4) Gibb BE, Abela JR. Emotional abuse, verbal victimization, and the development of children's negative inferential styles and depressive symptoms. Cognit Ther Res 2008;32:161-176.

5) An EM, Lee JY, Chung IJ. The effect of emotional abuse in childhood on peer attachment and teacher attachment: the moderating effect of academic achievement. J Adolesc Welf 2013;15:201-226.

6) Reyome ND. Childhood emotional maltreatment and later intimate relationships: themes from the empirical literature. J Aggress Maltreat Trauma 2010;19:224-242.

7) Stoltenborgh M, Bakermans-Kranenburg MJ, Van IJzendoorn MH. The neglect of child neglect: a meta-analytic review of the prevalence of neglect. Soc Psychiatry Psychiatr Epidemiol 2013;48:345355.

8) Simons RL, Whitbeck LB, Conger RD, Wu CI. Intergenerational transmission of harsh parenting. Dev Psychol 1991;27:159-171.

9) Wallin DJ. Attachment in psychotherapy. New York: The Guilford press;2007. p.64-67.

10) Lee JM, Song SM, Doh HS. Intergenerational transmission of parenting styles between grandparents and parents. J Kor Home Manage Assoc 2011;29:85-97.

11) Kim HY, Seok MS. The effects of abusive experience in childhood on child maltreatment: the mediating effects of the characteristics of parents and family relationship. Kor Acad Child Welf 2003;16: 71-97. 
12) Kim JA. Study on early childhood preservice teachers' cognition of child abuse and child abuse reporting system. J Cult Exchange 2014; 3:99-125.

13) Kim SJ, Lee JY. The factors influencing elementary school teachers' reporting intention and behavior in relation to child abuse. Korean J Child Stud 2013;34:39-58.

14) Lee SW, Cha WC, Shin TG, Sim MS, Jo IJ, Song KJ, et al. A survey of emergency healthcare workers' views about child abuse. Korean J Med Ethics 2014;17:85-93.

15) Hong SO, Lee OK. Parents of elementary students perception of child abuse in Busan. Kor J Child Educ 2010;19:75-90.

16) Kim KH, Park NR, Choi JA, editors. Child Abuse \& Neglect Korea 2016. Ministry of Health and Welfare, National Child Protection Agency 2016 [serial online] 2017 nov 17 [cited 2018 Jun 1]. Available from URL: http://www.korea1391.go.kr/new/bbs/board.php?bo table $=$ report\&wr_id $=9867$.

17) Seo DM, Yeun SY. The relationship among day care center teacher's job stress, awareness and action by self-assessment of the infant abuse. Early Child Educ Res Rev 2016;20:193-216.

18) Boyle MH, Offord DR, Racine Y, Fleming JE, Szatmari P, Sanford M. Evaluation of the revised ontario child health study scales. J Child Psychol Psychiatry 1993;34:189-213.

19) Kim SJ, Chung IJ. A longitudinal study of persistent and recency effects of child maltreatment on depression, anxiety and aggression. J Kor Soc Child Welf 2013;43:1-28.

20) Poole JC, Dobson KS, Pusch D. Do adverse childhood experiences predict adult interpersonal difficulties? The role of emotion dysregulation. Child Abuse Negl 2018;80:123-133.

21) Widom CS, Czaja S, Dutton MA. Child abuse and neglect and intimate partner violence victimization and perpetration: a prospective investigation. Child Abuse Negl 2014;38:650-663.

22) Park YK, Kang YJ. Behavior, knowledge and attitude on smoking of primary school children. J Korean Acad Fam Med 1996;17:798-809.

23) Shin EJ, Kim JM, Yoon JM. The effects of childhood interpersonal traumatic experience on self-system traumatization in college students: the dual mediating effect of emotional intelligence and multidimensional experiential avoidance. Kor J Child Psychother 2017; 12:89-106.

24) Hong SY, Lee SY. The relationship between emotional abuse and borderline personality disorder traits: mediating effects of emotional clarity and experiential avoidance. Kor J Counsel 2013;14:30033021.

25) Kim EJ, Kim JS. Relationship between childhood emotional abuse and the level of depression among college students: the mediating effect of emotional regulation difficulties. Kor J Counsel 2008;9: 1505-1520.

26) Kim HR, Hong HY. The influence of emotional abuse in childhood on dysfunctional anger expression of university students: the mediating effects of traumatized self-system and internalized shame. Kor J Counsel 2017:18:321-340.

27) Barlow J, Davis H, McIntosh E, Jarret, P, Mockford C, StewartBrown S. Role of home visiting in improving parenting and health in families at risk of abuse and neglect: results of a multicentre randomised controlled trial and economic evaluation. Arch Dis Child 2007;92:229-233.

28) DuMont K, Mitchell-Herzfeld S, Greene R, Lee E, Lowenfels A, Rodriguez M, et al. Healthy Families New York (HFNY) randomized trial: effects on early child abuse and neglect. Child Abuse Negl 2008;32:295-315.

29) Levey EJ, Gelaye B, Bain P, Rondon MB, Borba CP, Henderson DC, et al. A systematic review of randomized controlled trials of interventions designed to decrease child abuse in high-risk families. Child Abuse Negl 2017;65:48-57.

30) Kim HJ. The effect of parents education with PET and reality therapy on the changes in parent's attitude of upbringing and communication between parents and children. Kor J Parent Educ 2007;4: 95-121. 